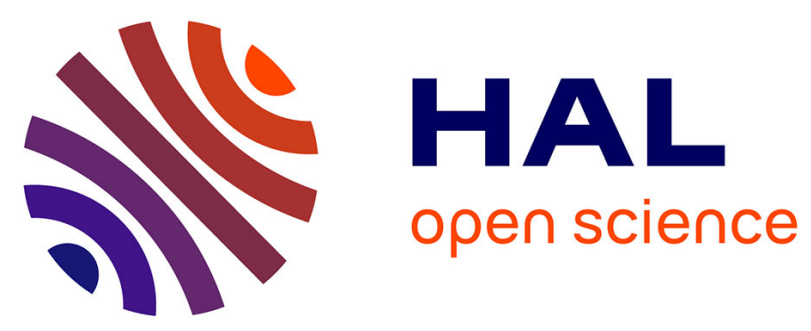

\title{
Controlled Nanoscale Topographies for Osteogenic Differentiation of Mesenchymal Stem Cells
}

Catarina R Pedrosa, Didier Arl, Patrick Grysan, Irfan Khan, Stéphanie Durrieu, Sivashankar Krishnamoorthy, Marie-Christine Durrieu

\section{To cite this version:}

Catarina R Pedrosa, Didier Arl, Patrick Grysan, Irfan Khan, Stéphanie Durrieu, et al.. Controlled Nanoscale Topographies for Osteogenic Differentiation of Mesenchymal Stem Cells. ACS Applied Materials \& Interfaces, 2019, 11 (9), pp.8858-8866. 10.1021/acsami.8b21393 . hal-02157703

\section{HAL Id: hal-02157703 https://hal.science/hal-02157703}

Submitted on 17 Jun 2019

HAL is a multi-disciplinary open access archive for the deposit and dissemination of scientific research documents, whether they are published or not. The documents may come from teaching and research institutions in France or abroad, or from public or private research centers.
L'archive ouverte pluridisciplinaire HAL, est destinée au dépôt et à la diffusion de documents scientifiques de niveau recherche, publiés ou non, émanant des établissements d'enseignement et de recherche français ou étrangers, des laboratoires publics ou privés. 


\section{Controlled Nanoscale Topographies for Osteogenic}

\section{Differentiation of Mesenchymal Stem Cells}

Catarina R. Pedrosa ${ }^{\ddagger \| \dagger \S}$ Didier Arl,$^{\S}$ Patrick Grysan, ${ }^{\S}$ Irfan Khan, ${ }^{\dagger} \|^{+}$Stéphanie Durrieu, ${ }^{\mathbb{\$} !}$

Sivashankar Krishnamoorthy, ${ }^{\S, *, \Delta}$ Marie-Christine Durrieu ${ }^{\ddagger} \| \dagger, *, \Delta$

$\$$ Université de Bordeaux, Chimie et Biologie des Membranes et Nano-Objets (UMR5248

CBMN), Pessac, France

$\|_{\text {CNRS, CBMN UMR5248, Pessac, France }}$

${ }^{\dagger}$ Bordeaux INP, CBMN UMR5248, Pessac, France

${ }^{\S}$ Materials Research and Technology (MRT) Department, Luxembourg Institute of Science and Technology (LIST), Belvaux, Luxembourg

$\mathbb{P}$ Université de Bordeaux, ARNA laboratory, Bordeaux, France

•INSERM, U1212 - CNRS UMR 5320, ARNA laboratory, Bordeaux, France

KEYWORDS: nanoscale, topographies, block copolymer self-assembly, mesenchymal stem cells, osteogenic differentiation 


\section{ABSTRACT}

Nanotopography with length scales of the order of extracellular matrix elements offers the possibility of regulating cell behavior. Investigation of the impact of nanotopography on cell response has been limited by inability to precisely control geometries, especially at high spatial resolutions, and across practically large areas. In this paper, we demonstrate well-controlled and periodic nanopillar arrays of silicon and investigate their impact on osteogenic differentiation of human mesenchymal stem cells (hMSCs). Silicon nanopillar arrays with critical dimensions in the range of 40-200 $\mathrm{nm}$, exhibiting standard deviations below 15\% across full wafers were realized using self-assembly of block copolymer colloids. Immunofluorescence and quantitative polymerase chain reaction (RT-qPCR) measurements reveal clear dependence of osteogenic differentiation of hMSCs on the diameter and periodicity of the arrays. Further, the differentiation of hMSCs was found to be dependent on the age of the donor. While osteoblastic differentiation was found to be promoted by the pillars with larger diameters and heights independent of donor age, they were found to be different for different spacings. Pillar arrays with smaller pitch promoted differentiation from a young donor, while a larger spacing promoted those of an old donor. These findings can contribute for the development of personalized treatments of bone diseases, namely novel implant nanostructuring depending on patient age. 


\section{INTRODUCTION}

The interaction of a material with biological tissues is known to impact initial protein adsorption on its surface and the subsequent cell response, namely its adhesion, proliferation or death. ${ }^{1,2}$ Cell-material interface can be therefore seen as a complex system comprising three main players: material, molecules on its surface, and adherent cells. The understanding of this interplay at the length scales of cells (microscale) or even molecules (nanoscale) is of extreme interest for the improvement of implants used in dentistry or orthopedics, the improvement of the properties of other biomaterials, and the understanding of in vivo cell microenvironment. ${ }^{3}$ In particular for bone tissue engineering studies, hMSCs are promising candidates due to their ability to proliferate and to differentiate into various lineages, including osteoblastic lineage. ${ }^{4}$ The interaction of a cell with a material topography was first observed in 1911 by Harrison, and it has been investigated at different scale regimes since then. ${ }^{5,6}$ Nanostructures including holes, posts and grooves have been shown to elicit specific cell responses on several cell types, namely fibroblasts, neurons and osteoblasts without the need of additional growth factors or other chemical cues. $^{7}$

hMSC differentiation potential has been shown to evolve with donor age. ${ }^{8,9}$ Aging is known to be responsible for lower proliferation rate, greater extent of senescence and apoptosis. ${ }^{10-12}$ Hence, the possible clinical use of MSCs from elderly people to treat bone diseases, such as osteoporosis, may be impaired by such drawbacks. Yet, to the best of our knowledge, the investigation of osteogenic differentiation of MSCs from donors of different age on nanoscale topographies has not been performed. Since it is understood that material nanostructuring can convey specific cues to lead to a specific cell behavior, we investigated osteoblastic 
differentiation of hMSCs on nanopillar arrays for young and old donors to have an insight on how such surfaces can be utilized to control cell differentiation according to patient age.

As previously referred, conflicting findings concerning the impact of nanotopographies on cell response are found in the literature, which can probably be related with the use of different cell culture protocols, regulating hMSC fate in different ways. In this study, we investigated the influence of controlled nanopillar arrays per se on the differentiation of hMSCs into the osteoblastic lineage. Cells were cultured on the nanostructured samples in a basal medium to avoid the influence of any other parameter besides topography. The fabrication of the nanoscale pillar arrays was based on the self-assembly of amphiphilic diblock-copolymers (BCPs) allowing the creation of polymeric masks for lithography. These micelle-based templates are an attractive alternative to other lithographic techniques, namely electron-beam lithography, due to their ease of formation on large surfaces, orthogonal control over geometric variables in steps down to $5 \%$ of their mean value, short processing times, lower costs, and compatibility with a wide range of substrates. ${ }^{13-16}$ Few studies showed the application of BCP self-assembly for the investigation of cell behavior, either for an accurate control of the presentation of molecules influencing cell adhesion or differentiation to the cells in culture, or for understanding the impact of nanoscale topographies on cells. ${ }^{17-23}$ Sjöstrom and McNamara have used BCP reverse micelles to create masks for the selective anodization of titanium surfaces, translating the polymeric template into the titanium sample, to study the impact of nanopillar height on the differentiation of hMSCs. ${ }^{20-}$ ${ }^{22}$ The nanopillars fabricated were distributed in a hexagonal array, and their top diameter was directly related with the diameter of the block copolymer micelles. The authors reported that titania pillars with diameters of 20 to $30 \mathrm{~nm}$ and $15 \mathrm{~nm}$ height are able to promote osteogenic differentiation of hMSCs cultured in basal medium, independently of feature separation (30 to 
$105 \mathrm{~nm}$ ) and organization. ${ }^{20-22}$ Contrarily, pillars of titania with larger dimensions (200 nm diameter, $450 \mathrm{~nm}$ spacing, $180 \mathrm{~nm}$ height) showed a positive impact on the osteodifferentiation of hMSCs in a work performed by de Peppo et al. ${ }^{23}$ It is worth noting that similar to the previously referred works of Oh and Park, the composition of cell culture media used were not the same, which may be one of the causes for divergences in the attained results. Whereas Sjöstrom and McNamara used a basal medium for hMSC culture, de Peppo used an osteogenic differentiation medium. ${ }^{20-23}$ There is still the need to continue investigating which geometric dimension (width, height, spacing) has more impact over hMSC behavior, particularly regarding osteogenic differentiation. With this aim, nanoscale pillar arrays with fine-tunable dimensions and quasi-hexagonal distribution were fabricated on silicon substrates and used for the culture of hMSCs for investigation of their impact on cell fate. Even though titanium and its alloys are the most common options as materials for bone implants due to their high biocompatibility and good mechanical properties, silicon was selected as model substrate for this study. ${ }^{24}$ The extensive development of techniques for silicon structuration in electronics, its ease of patterning compared with titanium, together with its good biocompatibility make it a more appropriate choice of material for the fabrication of features with characteristic dimensions of a few nanometers. The influence of silicon nanostructures on cell behavior was studied by immunofluorescence and RT-qPCR. Such techniques allowed the evaluation of expression of markers related with osteogenic differentiation of hMSCs, namely runt-related transcription factor 2 (Runx2), and type I collagen (COL1A1), expressed during early differentiation; osteopontin (OPN), and osteocalcin (OCN), expressed in late differentiation. ${ }^{25}$ 


\section{METHODS}

Materials. Polystyrene-block-poly(2-vinylpyridine) (PS-b-P2VP) (Mw 55000-b-50000 g/mol and $248000-\mathrm{b}-195000 \mathrm{~g} / \mathrm{mol}$, polydispersity indexes 1.05 and 1.08 respectively) were purchased from Polymer Source Inc (Montreal, Canada) and used without further purification. All solvents and surfactants were purchased from Sigma Aldrich, unless stated otherwise. Prime grade silicon wafers with a thermally grown silicon dioxide layer of $25 \mathrm{~nm}$ thickness were acquired from Siegert Wafer (Aachen, Germany). hMSCs from bone marrow and osteogenic differentiation medium were acquired from PromoCell (Heidelberg, Germany). Basal culture medium aMEM and fetal bovine serum (FBS) were purchased from Gibco, ThermoFisher Scientific (France). All the reagents used in DNA digestion and RNA retrotranscription were acquired from ThermoFisher Scientific. The primers used for RT-qPCR were acquired at Sigma-Aldrich, whereas SsoAdvanced ${ }^{\mathrm{TM}}$ Universal SYBR ${ }^{\circledR}$ Green Supermix was purchased from Bio-Rad. Bovine serum albumin (BSA) and sample mounting media with DAPI (Fluoroshield ${ }^{\text {TM }}$ with DAPI) were purchased from Sigma-Aldrich. The primary antibody against Runx2 was purchased from Cell Signaling Technology Europe (Netherlands). Primary antibodies against OPN, Sox9, COL2A1 were purchased from Santa Cruz Biotechnology (USA). Primary antibodies against PPAR $-\gamma$ and adiponectin were purchased from Abcam (France). Secondary antibodies were acquired from Invitrogen, ThermoFisher Scientific.

Nanopillar fabrication. Si substrates with $25 \mathrm{~nm}$ of thermally grown oxide layers $(25 \mathrm{~nm}$ $\mathrm{SiO} 2 / \mathrm{Si}$ ) were cleaned by exposing them to oxygen plasma reactive ion etching (PlasmaTherm 790 RIE, FL, USA) at low DC bias, followed by use of carbon dioxide snow jet to any small sized particles prior to nanopillar preparation. Silicon nanopillar arrays were prepared using protocol described by Krishnamoorthy and coworkers. ${ }^{13}$ Briefly, quasi-hexagonally ordered 
copolymer template with desired periodicity were obtained on $25 \mathrm{~nm} \mathrm{SiO} / 2 \mathrm{Si}$ by spin coating copolymer reverse micelle films from m-Xylene solutions. The substrates were then subjected to brief $\mathrm{Ar} / \mathrm{O}_{2}$ plasma descumming (18 sccm Ar $/ 2 \mathrm{sccm} \mathrm{O}, 4$ mTorr, $4 \mathrm{~W}$ ) for descumming the thin layer of polystyrene between the features, and subsequently transferred into thermal oxide layer by $\mathrm{CHF}_{3} / \mathrm{Ar}\left(12 \mathrm{sccm} \mathrm{CHF}_{3} / 38 \mathrm{sccm} \mathrm{Ar}\right.$, at $\left.-90{ }^{\circ} \mathrm{C}, 30 \mathrm{mTorr}, 200 \mathrm{~W}\right)$ and then into Si by $\mathrm{SF}_{6} / \mathrm{O}_{2}$ plasma (50 sccm $\left.\mathrm{SF}_{6} / 10 \mathrm{sccm} \mathrm{O}_{2}, 10 \mathrm{mTorr}, 25 \mathrm{~W}\right)$. Any remaining silica mask was removed by chemical etching with hydrofluoric acid $(2 \% \mathrm{v} / \mathrm{v})$. The attained polymeric arrays as well as the nanopillar arrays were characterized in detail by AFM (Innova, Bruker, MA, USA) and SEM (FIB-SEM, Helios 650, FEI Company, OR, USA).

XPS characterization. Samples were characterized by XPS to confirm that surface chemistry was identical on all surfaces. A K-Alpha (XPS system (ThermoFisher Scientific) with a monochromated AlKa source was utilized at $100 \mathrm{~W}$, spot size of $400 \mu \mathrm{m}$. For each condition, 5 regions were analyzed to confirm the uniformity of the surface treatment.

Cell culture. Nanopillar chips were sterilized in $70 \%$ ethanol overnight prior to their use as substrates for cell culture. hMSCs from bone marrow from two donors of 36 or of 65 years old were seeded at passage five on the prepared samples at an initial density of $104 \mathrm{cells} / \mathrm{cm}^{2}$. During the first 4 hours, cells were kept in serum-free medium to ensure cell interaction directly to the material surface, and incubated at $37{ }^{\circ} \mathrm{C}, 5 \% \mathrm{CO}_{2}$. Afterwards, medium was changed to $\alpha \mathrm{MEM}$ completed with $10 \%$ FBS, afterwards referred to as basal medium. Culture medium was replaced twice a week, and hMSCs were cultured for 2 weeks. Protein and gene expression were investigated by immunofluorescence assays and RT-qPCR.

Immunofluorescence assays. Immunostaining was performed after 2 weeks of cell culture to investigate the expression of osteogenic markers. Cells were fixed with paraformaldehyde (4\%), 
permeabilized with Triton-X $100(0.5 \%)$ and ice-cold methanol. To avoid non-specific interactions, samples were incubated with BSA (1\%). Samples were subsequently incubated with primary antibodies for 1 hour at $37{ }^{\circ} \mathrm{C}$. After washing with Tween-20 (0.05\%), samples were incubated for 1 hour at $37^{\circ} \mathrm{C}$ with the secondary antibodies IgG coupled with AlexaFluor ${ }^{\mathrm{TM}} 488$ or IgG coupled with AlexaFluor ${ }^{\mathrm{TM}}$ 647. Samples were again washed with a solution of Tween-20 $(0.05 \%)$ and mounted and counterstained with DAPI. Samples were observed using an epifluorescence microscope Leica DM5500B. Immunofluorescence assays for investigation of osteoblastic differentiation (Runx2 and OPN) were performed for $n=3$, considering the expression of at least 100 cells per sample. Adipogenic (PPAR- $\gamma$ and adiponectin) and chondrogenic (Sox9 and COL2A1) differentiation, the assays were only performed once $(n=1)$, and the fluorescence signal was measured in 20 cells per sample.

RT-qPCR. Total RNA was isolated using RNeasy Mini Kit (QIAGEN), and genomic DNA was removed using TURBO DNA-free kit. Isolated RNA was quantified using a NanoDrop 1000 (ThermoFisher Scientific) and RNA integrity was assessed using an Agilent bioanalyzer 2100 with a RNA 6000 Nano kit (Agilent, USA). cDNA was synthesized from 500 ng of total RNA with the help of random primers and Maxima Reverse Transcriptase. RNA retrotranscription reaction included two main steps: incubation at $50^{\circ} \mathrm{C}$ for 1 hour, followed by an incubation at 72 ${ }^{\circ} \mathrm{C}$ for $15 \mathrm{~min}$. Aliquots of cDNA underwent dye-based RT-qPCR for the study of four genes (primers listed in Table 1). RT-qPCR was performed using 4 ng of cDNA, and primers at a concentration of $500 \mathrm{nM}$, for a final volume of $10 \mu \mathrm{L}$. RT-qPCR was performed using a CFX Connect ${ }^{\mathrm{TM}}$ Real-Time PCR System (Bio-Rad), using two genes of reference: RPC53 and PPIA. Forty PCR amplification cycles were performed for each experiment, and consisted on incubating the solution at $95{ }^{\circ} \mathrm{C}$ for $5 \mathrm{~s}$, followed by an incubation at $60^{\circ} \mathrm{C}$ for $10 \mathrm{~s} . C q$ values 
for the genes of interest were normalized against two reference genes selected using BestKeeper: PPIA and RPC53. ${ }^{26}$ The relative expression levels were calculated using the comparative method $(\triangle \triangle C q)$ and gene expression was normalized using flat Si sample as control. For each condition, three biological samples were tested, for which four technical replicates were done.

Table 1. Primers used for RT-qPCR assays.

\begin{tabular}{|c|c|c|c|}
\hline & Gene & Primer sequence & Amplicon / bp \\
\hline \multirow{4}{*}{$\begin{array}{l}\text { Reference } \\
\text { genes }\end{array}$} & & 5'-ACCCTGGCTGACCTGACAGA-3' (Forward) & \multirow{2}{*}{71} \\
\hline & & 5'-AGGAGTTGCACCCTTCCAGA-3' (Reverse) & \\
\hline & \multirow{2}{*}{ PPIA } & 5'-CGGGTCCTGGCATCTTGT-3' (Forward) & \multirow{2}{*}{81} \\
\hline & & 5'-CAGTCTTGGCAGTGCAGATGA-3' (Reverse) & \\
\hline \multirow{6}{*}{$\begin{array}{c}\text { Genes of } \\
\text { interest }\end{array}$} & \multirow{2}{*}{ Runx2 } & 5'-AAGTGCGGTGCAAACTTTCT-3' (Forward) & \multirow{2}{*}{90} \\
\hline & & 5'-TCTCGGTGGCTGGTAGTGA-3' (Reverse) & \\
\hline & & 5'-ACATGTTCAGCTTTGTGGACC-3' (Forward) & \multirow{2}{*}{117} \\
\hline & & 5'-TGATTGGTGGGATGTCTTCGT-3' (Reverse) & \\
\hline & \multirow{2}{*}{$\mathrm{OCN}$} & 5'-GACTGTGACGAGTTGGCTGA-3' (Forward) & \multirow{2}{*}{119} \\
\hline & & 5'-CTGGAGAGGAGCAGAACTGG-3' (Reverse) & \\
\hline
\end{tabular}

Statistical analysis. All data are expressed as mean \pm standard error of the mean, except if stated otherwise. Statistical analyses were performed using MatLab (MathWorks, USA) in the case of SEM data, NanoScope Analysis (Bruker, USA) for AFM data, CFX Maestro Software (Bio-Rad, USA) for RT-qPCR data, and GraphPad Prism (USA) for immunofluorescence data. Significant differences were considered for $\mathrm{p}$-values $<0.05$. 


\section{RESULTS}

Nanopillar fabrication. The experimental strategy to obtain nanopillar arrays was based on the process developed by Krishnamoorthy. ${ }^{13}$ Spin-coating of the PS-b-P2VP reverse micelle solutions on thoroughly cleaned substrates allowed the creation of organized, hexagonally distributed templates on 4 inch wafers, without the need for any further solvent annealing processing. The possibility of creating highly controlled nanoarrays on full wafers was one of the main considerations behind the choice of this process. hMSC culture and characterization required the utilization of hundreds of chips to ensure that experiments were reproducible and that statistically relevant results were obtained.

The use of BCPs of different molecular weights $(M w)$ and block ratios allowed the fabrication of arrays of varying characteristic dimensions, as shown in Figure 1. Furthermore, the dependence of the array periodicity on evaporation speeds and solution concentrations was also used to arrive at desired pitch. Average feature diameter was determined for each condition over full wafer area by scanning electron microscopy (SEM), and the corresponding center-to-center distances, and feature densities by atomic force microscope (AFM), as summarized in Table 2.
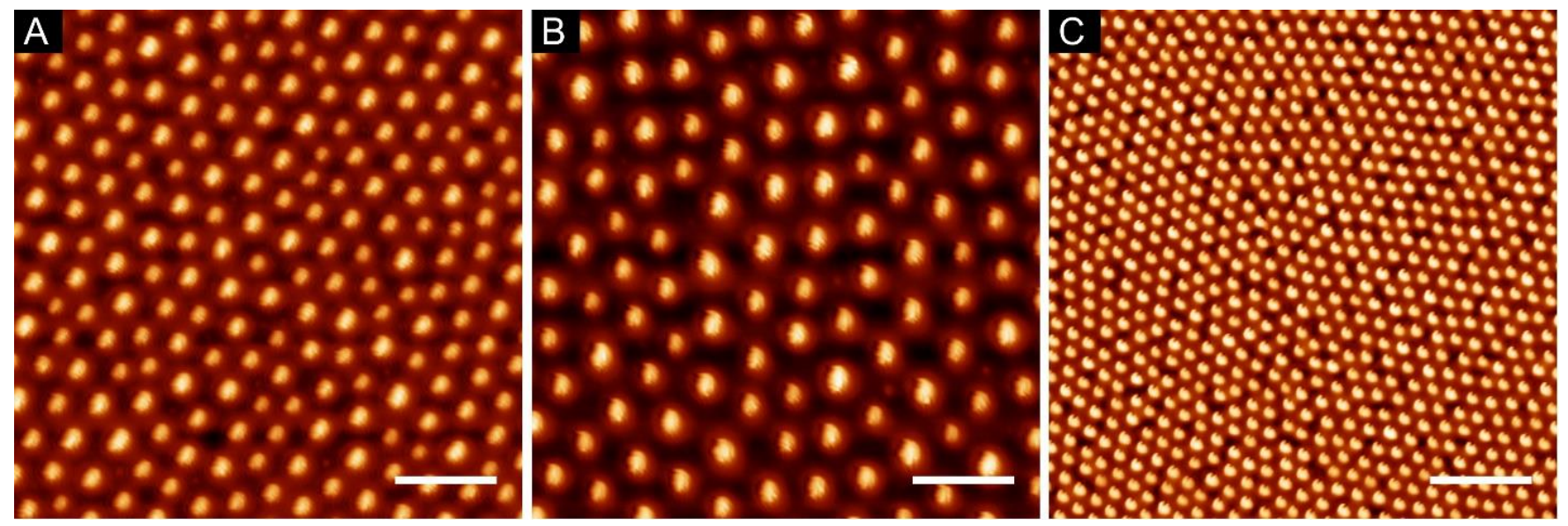

Figure 1. Representative AFM images of BCP templates A, B, and C. Scale bar $400 \mathrm{~nm}$. 
Table 2. Average characteristic dimensions of the produced BCP reverse micelle arrays. For simplicity, the arrays were labelled as A, B, and C. (Values represented as mean \pm standard deviation)

\begin{tabular}{ccccc}
\hline Label & Mw $/ \mathrm{kg} / \mathrm{mol}$ & Spin speed $/ \mathrm{rpm}$ & Diameter $/ \mathrm{nm}$ & Periodicity $/ \mathrm{nm}$ \\
\hline A & $148-\mathrm{b}-195$ & 2000 & $64 \pm 6$ & $135 \pm 14$ \\
B & $148-\mathrm{b}-195$ & 5000 & $60 \pm 8$ & $197 \pm 23$ \\
C & $55-\mathrm{b}-50$ & 5000 & $52 \pm 4$ & $68 \pm 4$ \\
\hline
\end{tabular}

A small variation in periodicity, as well as a deviation from the expected hexagonal packing was observed during SEM characterization across the wafer surface, as depicted in Table 3, primarily due to different speeds of solvent evaporation during substrate coating. Nonetheless, the impact of such deviations on the full samples was within the range observed in previous studies, so it could be disregarded during the subsequent steps. ${ }^{13,27}$ Another interesting parameter to evaluate was the density of micelles on the surface, also presented in Table 3. 
Table 3. Coefficients of variation (CV) for feature diameter and periodicity across wafers, percentage of features in a correct hexagonal packing, and density of features for the two $\mathrm{BCP}$ coated at $5000 \mathrm{rpm}$ on 4 inch wafers.

\begin{tabular}{cccccc}
\hline Mw/kg/mol & Region & CV diameter & CV periodicity & $\begin{array}{c}\text { Coordination } \\
\text { number 6 }\end{array}$ & Density $/ \mu \mathrm{m}^{-2}$ \\
\hline \multirow{3}{*}{$55-\mathrm{b}-50$} & Center & $11 \%$ & $12 \%$ & $51 \%$ & 115 \\
& Mid & $9 \%$ & $10 \%$ & $65 \%$ & 136 \\
& Edge & $8 \%$ & $11 \%$ & $58 \%$ & 106 \\
& Center & $12 \%$ & $12 \%$ & $62 \%$ & 26 \\
$148-\mathrm{b}-195$ & Mid & $12 \%$ & $10 \%$ & $54 \%$ & 22 \\
& Edge & $10 \%$ & $12 \%$ & $57 \%$ & 21 \\
\hline
\end{tabular}

Post etching characterization of the patterned wafers showed slight differences in feature dimensions from the initial ones. Once more, SEM was performed at full wafer scale to investigate the final characteristics of the nanopillar samples. These results are summarized in Table 4, and Figure 2 shows a detailed SEM view for a better comparison of all arrays. Wafers were subsequently treated with hydrofluoric acid and diced into $1 \mathrm{~cm}^{2}$ chips to be compatible with ordinary cell culture systems. 
Table 4. Average characteristic dimensions of the produced nanopillar arrays. Labels A,B,C were defined in Table 3. Labels 40/80 correspond to feature height.

\begin{tabular}{cccc}
\hline Label & Diameter $/ \mathrm{nm}$ & Periodicity $/ \mathrm{nm}$ & Height $/ \mathrm{nm}$ \\
\hline A40 & $105 \pm 14$ & $137 \pm 14$ & $42 \pm 6$ \\
A80 & $105 \pm 14$ & $141 \pm 12$ & $75 \pm 6$ \\
B40 & $102 \pm 10$ & $196 \pm 23$ & $39 \pm 3$ \\
B80 & $104 \pm 13$ & $201 \pm 23$ & $82 \pm 6$ \\
C40 & $58 \pm 4$ & $70 \pm 2$ & $47 \pm 4$ \\
C80 & $54 \pm 5$ & $73 \pm 3$ & $85 \pm 5$ \\
\hline
\end{tabular}



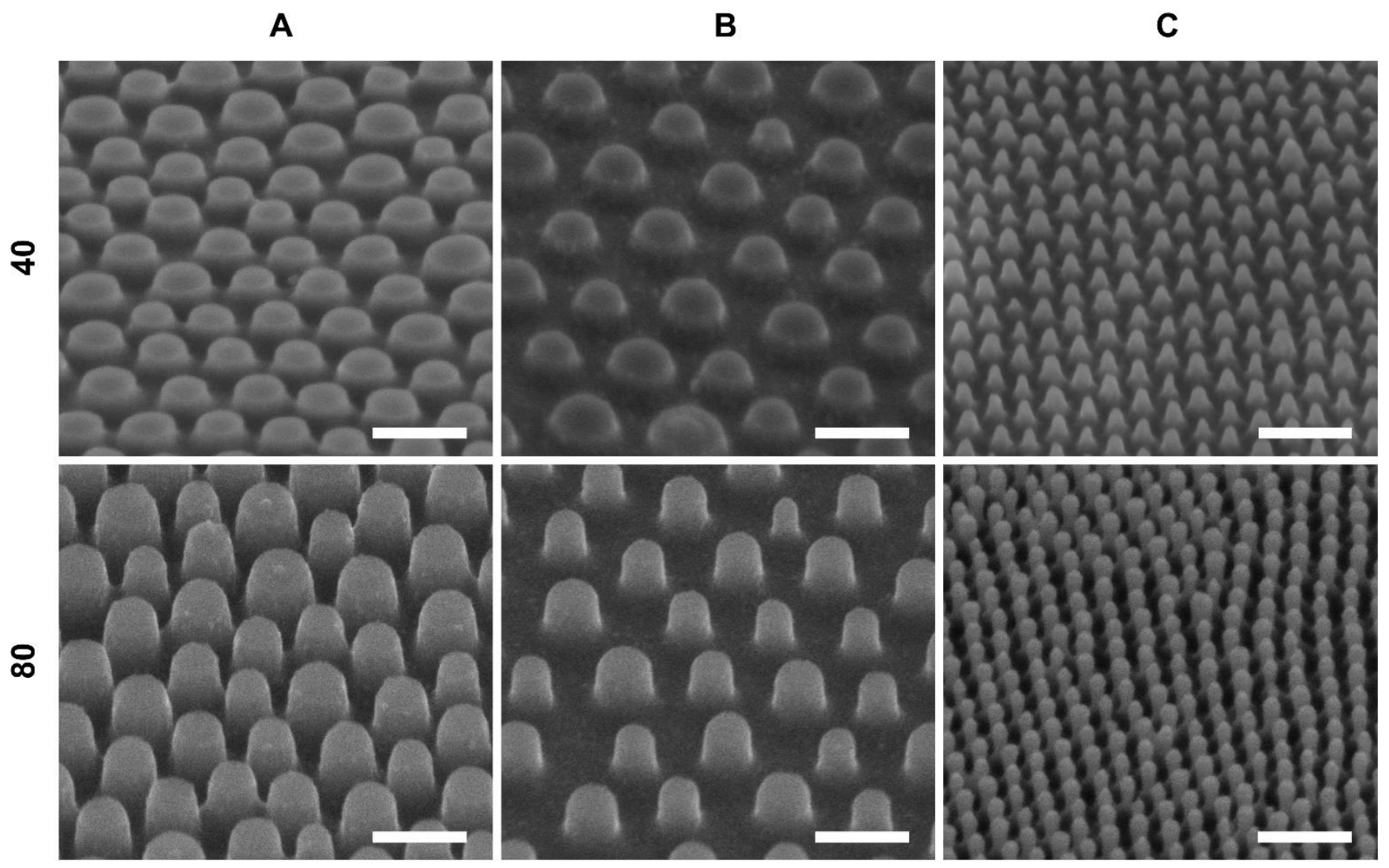

Figure 2. Details of SEM micrographs of nanopillar samples. Columns labels correspond to the labels A, B, C referred before. Lines 40 and 80 correspond to pillar heights of $40 \mathrm{~nm}$ or $80 \mathrm{~nm}$ respectively. Scale bar $200 \mathrm{~nm}$.

Since it is known that cells are able to sense and respond to not only surface topography, but also to its chemistry, samples were characterized be XPS in order to verify that the surface chemistry to which hMSCs would be subjected to was the same for all arrays. ${ }^{28,29}$ The results obtained after peak fitting are summarized in Table 5. 
Table 5. XPS characterization results of samples from all the topography conditions.

\begin{tabular}{cccccccccc}
\hline \multirow{2}{*}{ Element } & \multirow{2}{*}{ Bond } & $\mathrm{eV}$ & \multicolumn{7}{c}{ Atomic \% } \\
& & & $\mathrm{F}$ & $\mathrm{A} 40$ & $\mathrm{~A} 80$ & $\mathrm{~B} 40$ & $\mathrm{~B} 80$ & $\mathrm{C} 40$ & $\mathrm{C} 80$ \\
\hline \multirow{2}{*}{$\mathrm{Si}$} & $\mathrm{Si}^{0}$ & $98.9-99.3$ & 50.3 & 42.9 & 41.6 & 46.6 & 45.5 & 38.2 & 42.9 \\
& $\mathrm{SiOC}_{3}$ & $101.7-101.9$ & 2.1 & 2.5 & 3.4 & 1.8 & 1.8 & 1.9 & 1.6 \\
& $\mathrm{SiO}_{2} \mathrm{C}_{2}, \mathrm{SiO}_{3} \mathrm{C}$ & $102.7-103.1$ & 5.6 & 9.1 & 7.7 & 8.0 & 8.3 & 11.2 & 9.5 \\
& $\mathrm{C}-\mathrm{C}$ & $284.7-285.0$ & 10.3 & 12.2 & 14.4 & 12.3 & 12.0 & 12.6 & 12.9 \\
$\mathrm{C}$ & $\mathrm{C}-\mathrm{O}$ & $286.2-286.5$ & 3.2 & 2.8 & 3.3 & 3.4 & 3.0 & 3.4 & 3.7 \\
& $\mathrm{COOH}$ & $288.7-289.2$ & 0.6 & 0.7 & 0.7 & 0.8 & 0.5 & 0.6 & 0.4 \\
$\mathrm{~N}$ & $\mathrm{~N}-\mathrm{C}-\mathrm{O} \times$ & $401.7-401.8$ & 0.3 & 0.2 & 0.2 & 0.3 & 0.3 & 0.3 & 0.5 \\
$\mathrm{O}$ & $\mathrm{O}-\mathrm{C}$ & $532.2-532.6$ & 27.6 & 29.6 & 28.7 & 26.8 & 28.6 & 31.8 & 28.5 \\
\hline
\end{tabular}

Immunofluorescence. Immunofluorescence assays were primarily performed to evaluate the expression of proteins known to be related with differentiation into the osteoblastic lineage (Runx2, OPN). The role and temporal expression of the selected markers during hMSC differentiation have been extensively studied previously, which makes them good tools for the understanding of cell response to the fabricated nanostructured materials. ${ }^{25,30}$ Since Runx 2 is expressed in an early stage of differentiation into osteoblastic lineage, and OPN in a later phase, it could be possible to investigate to which extent the nanostructured samples were able to favor hMSC differentiation towards osteogenic lineage. Additionally, osteoblastic differentiation of hMSCs from a young and an old donor was characterized, to investigate possible variations between donors due to nanotopography. 
hMSC commitment to the osteoblastic lineage was characterized after 2 weeks of culture on the nanopatterned surfaces in basal media (an example of marker expression on a flat silicon substrate is represented in Figure 3). Fluorescence signal for each nanoarray was compared between topographies, and the results were normalized to a flat control for simplicity (Figure 4).
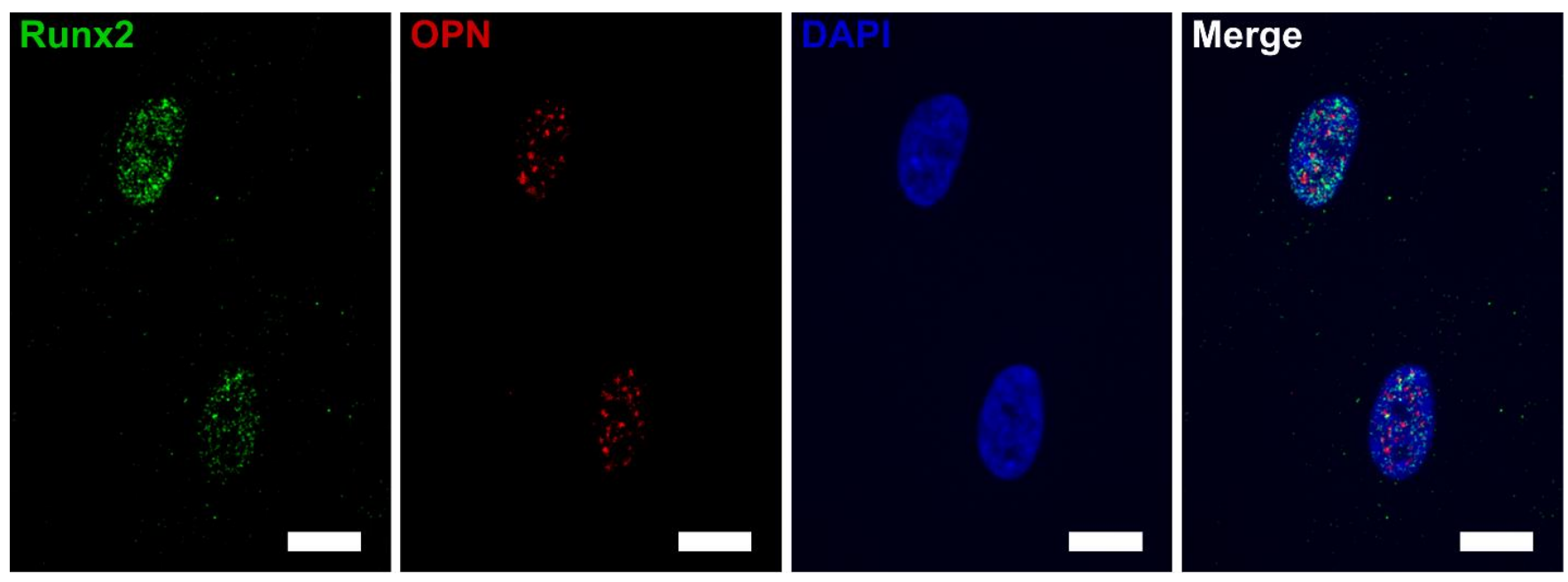

Figure 3. Example of immunofluorescence images obtained for the characterization of Runx2 and OPN expression (nucleus marked with DAPI) for understanding of intracellular distribution of these proteins on flat silicon. (Scale bar $15 \mu \mathrm{m}$ ). 
(i) Young donor
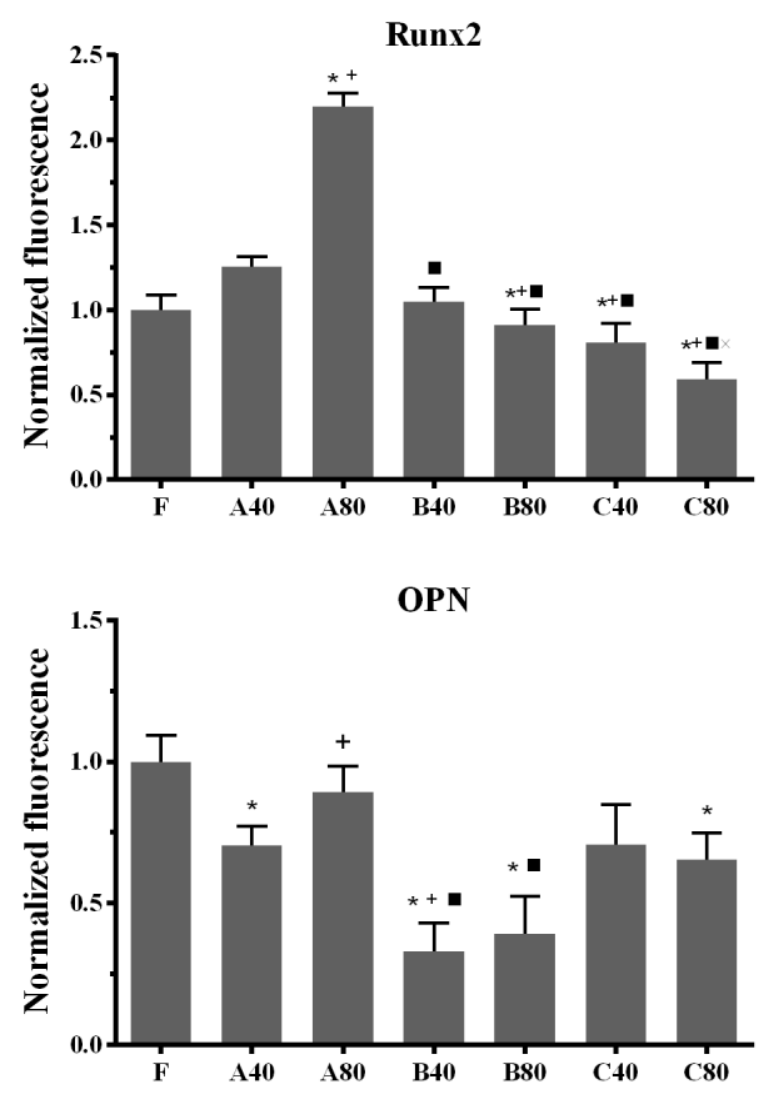

(ii) Old donor
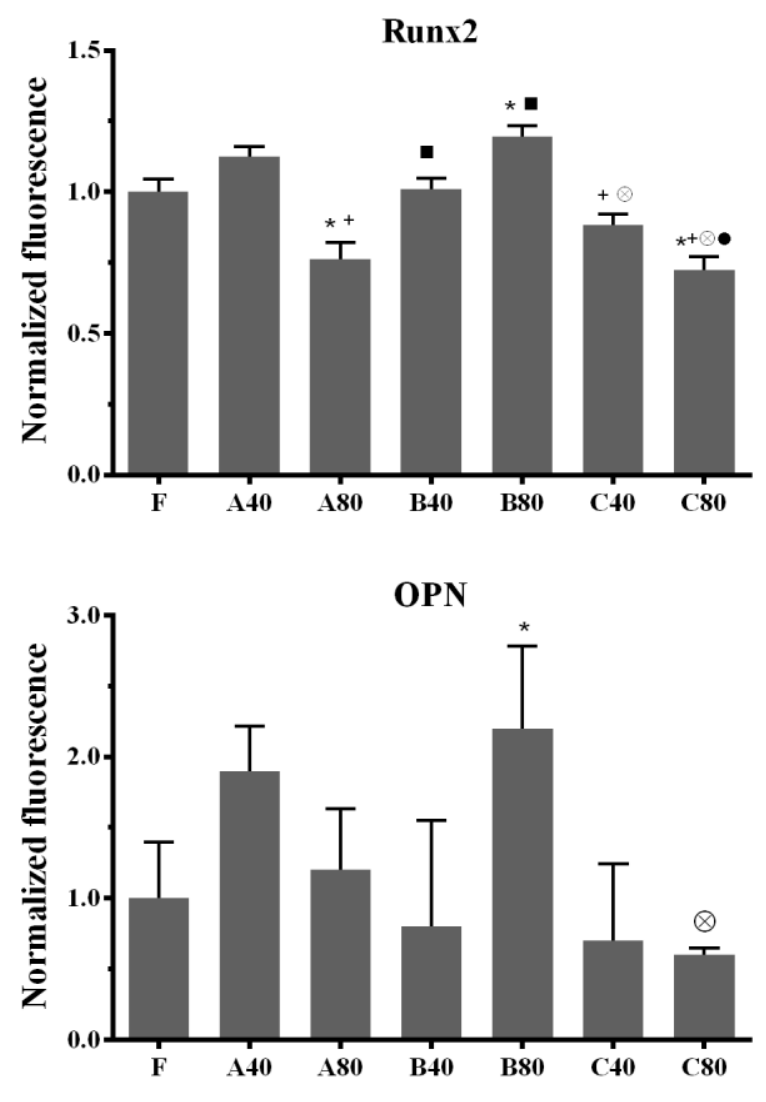

Figure 4. Fluorescence intensity related with the expression of markers for osteoblastic differentiation of hMSCs after 2 weeks of culture on the nanostructured Si samples in basal medium was normalized against flat Si (F) control. (i) Expression in cells from young donor. (ii) Expression in cells from old donor. ( ${ }^{*}$ represents significant differences from $\mathrm{F},{ }^{+}$from $\mathrm{A} 40$, from $\mathrm{A} 80, \otimes$ from B40, and $\bullet$ from B80) 
Expression of markers was found to be markedly different for cells from the two donors. Regarding the expression of the early osteogenic marker Runx2, hMSCs from a young donor (Figure 4i) show a very high signal for the pattern A80 when compared with the remaining conditions (2.2 fold higher signal compared with F), whereas in the case of the old donor (Figure 4ii) the highest Runx2 signal was observed on B80 samples (1.2 fold compared with control). This tendency was in agreement with the expression of the late differentiation marker studied (OPN). In Figure 4i, the fluorescence observed for young cells grown on A80 and C40 samples was similar to the fluorescence observed on control. However, all other nanostructures showed a lower signal than the flat control. The population of cells from an old donor had a very heterogeneous expression of OPN (Figure 4ii). Only significant differences were observed between $\mathrm{F}$ and B80, and B80 and C80. Expression on B80 pattern is approximately twice the signal observed on the control, which was consistent with the trend observed for Runx2.

To assess if the nanotopographies could potentially be used for the control of differentiation towards chondrocyte or adipocyte lineages, immunofluorescence assays were performed in parallel for cells from a young donor. Sox 9 and type II collagen (COL2A1) were selected as markers of chondrogenic differentiation, whereas PPAR- $\gamma$ and adiponectin were selected as markers of adipogenic differentiation of MSCs. ${ }^{30,31}$ No expression was observed regarding the adipogenic markers on any topography after 2 weeks (data not shown), indicating that the selected nanoarrays are not suitable to guide hMSC differentiation towards adipogenic lineage. On the other hand, immunostaining for chondrogenic markers indicated that the pattern B80 was particularly efficient on the enhancement of chondrogenic differentiation of hMSCs, as represented in Figure 5. 


\section{Sox9}

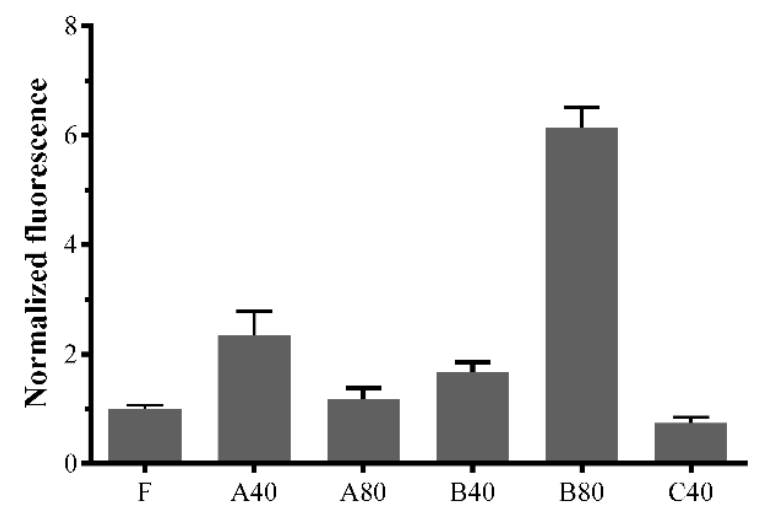

COL2A1

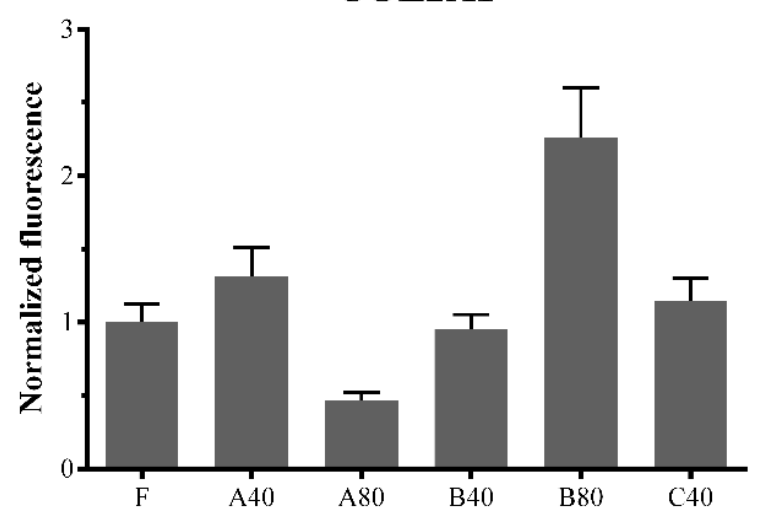

Figure 5. Normalized fluorescence intensity observed hMSCs cultured for 2 weeks on nanotopographies related with the expression with Sox 9 and COL2A1, the chondrogenic markers selected. Fluorescence was normalized against the flat control for simplicity of analysis.

RT-qPCR. Although it is not possible to ensure an accurate correlation between protein and gene expression, the selection of conditions for RT-qPCR assays was based on the previously obtained immunofluorescence results. The difficulties in correlating mRNA and protein expression are mainly due to variations in mRNA translation efficiency (which depends on ribosome density and their occupancy levels), protein stability, as well as experimental errors and noise associated to the assays. ${ }^{32,33}$ Nevertheless, since RT-qPCR experiments require a large amount of transcriptome, and it was necessary to pool cells from $4 \mathrm{~cm}^{2}$ (four samples for each condition), it was decided that gene expression would only be evaluated for the conditions granting the best results for osteogenic differentiation in immunofluorescence. As different tendencies were observed for cells from young and old donors, the best condition after the interpretation of immunofluorescence results for the young donor, i.e., A80, and for the old donor, that is, B80 were selected for the subsequent studies. 
After 2 weeks of culture on the selected nanopatterns, the differentiation stage of the cells was investigated. The expression of genes known to be expressed during early (Runx2, COL1A1) and late (OCN) stages of differentiation of hMSCs into osteoblasts was quantified to further investigate differences on the impact of the nanotopographies on hMSC differentiation (Figure 6).

(i) Young donor

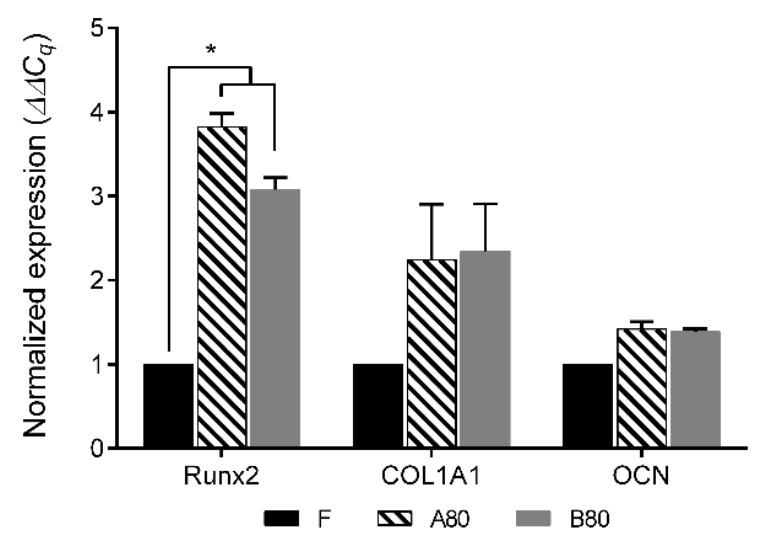

(ii) Old donor

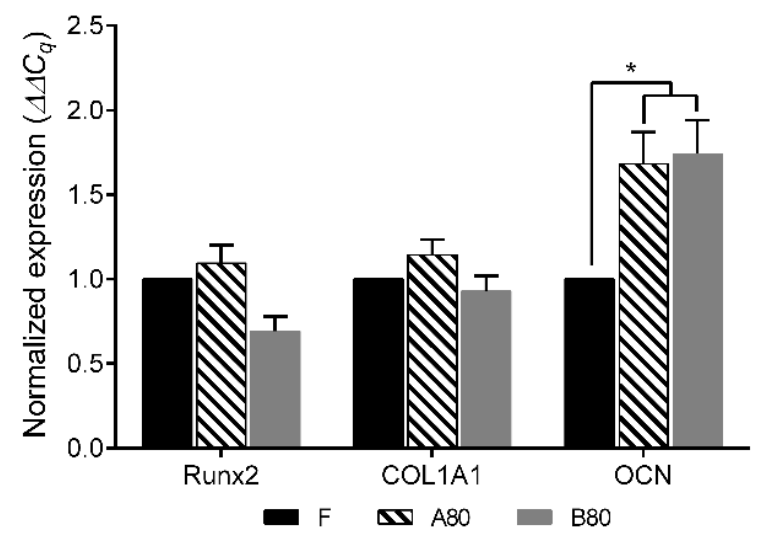

Figure 6. Normalized gene expression ( $\triangle \Delta C q$ method) of Runx2, COL1A1, and OCN in hMSCs after 2 weeks of culture in basal medium on the nanostructured samples, taking the flat Si surface (F) as control. $(\mathrm{n}=4)$. * represents significant differences from $\mathrm{F}$.

RT-qPCR results were in agreement with the trendlines observed by immunofluorescence. Concerning hMSCs from a young donor, Runx2 expression was significantly higher on nanostructured samples, especially for the A80 condition. Similarly, the expression of COL1A1, an early differentiation marker as Runx2, appeared to be enhanced on the nanotopographies, though the difference from control was not significant for the confidence interval selected. As 
COL1A1 is a protein characteristic of the ECM, it can be concluded that within each cell group, the rate of ECM production is variable, which contributes for the large error bars observed for the expression of COL1A1 after 2 weeks. OCN expression was comparable on the three substrates. It is therefore reasonable to deduce that, after 2 weeks, these cells were in an early osteoblastic differentiation stage.

On the other hand, cells from an older donor were able to differentiate faster on nanostructured surfaces than younger cells. In this case, OCN was over-expressed on nanostructured samples compared with the flat control, whereas the expression of Runx2 and COL1A1 were similar for all conditions. Such results indicate that the expression of Runx2 and COL1A1 (early markers of differentiation) is reduced on nanostructured samples, indicating that cells are in more differentiated stage towards osteoblasts. 


\section{DISCUSSION}

Nanoscale topographies. The modification of material properties, namely surface chemistry, topography, and mechanical characteristics, has been extensively investigated for the modulation of cell behavior, including their proliferation, adhesion, or differentiation abilities. ${ }^{28,29,31-33}$ In particular, a controlled modification of the topography of a material at nanoscale has demonstrated to be a powerful tool to control the differentiation of hMSCs into the osteogenic lineage as reviewed by Donelly, or Gui. ${ }^{2,34}$ Still, the creation of nanoscale topographies using traditional lithographic methods used in nanoelectronics, as electron-beam and focused-ion-beam lithography, have inherent drawbacks including high costs and low throughput (due to the time required to process a small die). ${ }^{35}$ Conversely, the use of BCP templates for lithography proves to be a viable alternative, allowing high feature density, with dimensions down to a few nanometers, faster sample processing, and lower costs, since it allows the creation of organized templates via simple spin-coating or dip-coating of a BCP solution onto a material. ${ }^{35}$ Typically, after coating on a substrate, these templates undergo a step of solvent or thermal annealing above their glass transition temperature to improve the ordering of the domains on the surface. ${ }^{14,27,36}$ Such step is very time-consuming, and can actually lead some non-uniformity across large surface areas, as full wafers (since every extra step of a process introduces a degree of uncertainty). Thus, in this study, reverse micelles of PS-b-P2VP were prepared in a selective solvent and used for lithography right after spin-coating, as described by Krishnamoorthy. ${ }^{13}$ Nanoscale pillar arrays were successfully created on full wafers making use of BCP selfassembly properties and common nanofabrication techniques used in electronic applications. These arrays show low variability of their characteristic dimensions across the wafer surface, and high process reproducibility. It was possible to control each geometric variable (diameter, 
spacing, height) independently in steps down to $5 \%$ of their mean value. These patterns can possibly be applied on different surfaces, namely non-planar, or soft polymeric materials, through the simple application of nanoimprint lithography, which allows a fast imprinting of the negative of the pattern on a resin that can be used as mask to etch the underlying substrate. Although the processing time was reduced following the current approach, several parameters were carefully controlled to decrease variability of the coatings. Nevertheless, once the set of variables was fine-tuned for the expected arrays, sample processing time was considerably shorter than the alternative approaches previously referred, and reproducible pillars arrays on full wafers were produced for subsequent use in cell culture.

The fact that it is known that hMSCs are able to sense differences in topography of a few nanometers, along with the need to replicate the cell studies to investigate statistically relevant cell responses, required the fabrication of highly reproducible and controlled nanoarrays on full wafers to have a sufficient number of nanostructured samples for cell culture. To the extent of our knowledge, there are no published studies on modulation of hMSC differentiation via nanoscale topographies on silicon. Investigation of hMSC response to similar nanoscale topographies has been more commonly reported on titanium dioxide or polymeric surfaces. ${ }^{20,23,37}$ Still, the fabricated Si nanostructures can potentially be interesting model surfaces for bone disease studies.

Investigation of hMSC response. Nanopillars of cylindrical shape (ensured by the use of a hard mask and highly controlled etching conditions) hexagonally distributed over a large surface (4 inch wafers) were obtained for hMSC studies. The possibility of controlling the characteristics of the fabricated arrays paved the way for the investigation of not only the most 
interesting range of dimensions of the nanofeatures able to favor hMSC osteogenic differentiation, but also which geometrical variable (diameter, spacing, height) would have more influence on this specific cell response.

The results obtained indicate that the geometries selected can promote osteogenic differentiation in a faster/greater extent than flat silicon surfaces. Still, differences in hMSC response to the patterns were observed between young and old donors. Whereas after 2 weeks of cell culture, younger cells show increased expression of osteogenic markers on A80 samples (diameter $100 \mathrm{~nm}$, height $80 \mathrm{~nm}$, spacing $140 \mathrm{~nm}$ ), old cells seem to differentiate faster on B80 patterns (same diameter and height, but larger spacing of $200 \mathrm{~nm}$ ). Despite the difference in spacing, it can be concluded that hMSCs are more prone to undergo osteoblastic differentiation when cultured on Si nanopillars of larger dimensions (diameter $100 \mathrm{~nm}$ ) than on pillars of smaller diameter $(50 \mathrm{~nm})$. Such result is in accordance with the work of de Peppo et al., who observed that larger nanofeature dimensions favor cell adhesion, spreading, and osteogenic differentiation of hMSCs. ${ }^{23}$ Still, it is important to note that the substrate material were different (titanium vs. silicon in the present work), and that, contrary to that study, in the present work, cells were always kept in a basal medium, without any further supplementation, as dexamethasone or $\beta$-glycerophosphate to induce osteodifferentiation. The utilization of basal media allowed the investigation of the influence of the material topography alone. Cells are not restricted to the differentiation into one lineage, but they can also proliferate maintaining their stemness, or differentiate into other lineages. On the contrary, the use of an osteogenic differentiation medium constrains cell differentiation to this specific lineage. In this case the effect of topography would be observed on the differentiation rate, with cells demonstrating a faster commitment towards the osteoblastic lineages on specific materials. Still, it would be 
necessary to accurately deconvolute the effects of topography and induction medium on cell behavior, including several control samples, which can be simplified using a basal medium for the whole experiment.

Immunofluorescence results indicate that the population of cells from a younger donor is considerably more homogeneous than from older donor, which can be noticed especially by the length or error bars for OPN expression. hMSCs from the old donor show rather longer error bars, evidencing that the expression of OPN diverges within this cell population. Nonetheless, RT-qPCR results confirm that hMSCs from the old donor are undergoing osteoblastic differentiation, notably on the selected nanostructures. Cells cultured on the nanostructures show a significantly increased expression of OCN gene than cells cultured on flat control. Moreover, since the earlier differentiation markers were expressed at similar levels on all surfaces, it can be concluded that cells from the old donor were in a late stage of differentiation of MSCs into osteoblasts. ${ }^{25}$ On the other hand, RT-qPCR indicated that cells from a younger donor were differentiating preferentially on nanostructured surfaces. Yet, after 2 weeks, these cells were still in an early stage of differentiation and would need a longer time in culture to reach the stage of differentiation of older hMSCs. An extra time point for a longer time in culture would be important to confirm such conclusion. A decrease in the expression of the early markers for A80 and B80 along with an increase of OCN would then be expected. Moreover, the observation of changes in cell morphology during differentiation process could be a relevant approach to further confirm cell differentiation on the different topographies.

Regarding the investigation of chondrogenic commitment, immunofluorescence showed that features with large diameter and height, and with increased separation (B80) would be the more adequate for the promotion of chondrogenic differentiation of hMSCs from a young donor. To 
the extent of our knowledge, MSC differentiation into chondrocytes on 2D surfaces without any biochemical modification is hardly feasible. ${ }^{38}$ Stimulation of chondrogenesis in vitro is normally achieved using hydrogels (3D) or 2D substrates coated with chondroitin, for instance. ${ }^{2,38}$ Further investigation of the possibility of using the nanopillar arrays prepared for studies of hMSC differentiation towards chondrogenic lineage would be of great interest. It is also worth noting that the alterations in ability to differentiate of hMSCs with age. Although hMSCs from a young donor were more prone to commit towards chondrogenic lineage when cultured on B80 arrays, the hMSCs from an older donor registered higher expression of osteogenic markers on the same arrays.

We believe that the cell seeding protocol followed in the present study is more adequate for the investigation of the impact of nanoscale topographies on cell behavior than the approaches previously reported. Contrary to most protocols found in literature, where hMSCs are seeded on materials in media with serum, here cells are seeded and incubated during the first 4 hours in medium without serum. ${ }^{20,23,39}$ Therefore, cells have time to interact directly with the nanostructures, whereas if the medium was supplemented with any sera, proteins would adsorb firstly and very rapidly on the material surface, and cells would adhere to the material coated with proteins. In the latter case, it is important to note that the adsorption of proteins causes not only a change in surface chemistry (that is also known to have an impact on hMSC behavior), but also in surface topography, since the features and proteins have comparable dimensions. These changes demand further characterization of the surface, which can be very troublesome, as protein adsorption cannot be accurately controlled. To avoid such complications, cells can simply be incubated during the first hours after seeding in a medium without proteins, as described here. 


\section{CONCLUSIONS}

Periodic nanopillar arrays with precise and independent control over diameter, height and periodicity were fabricated by pattern-transfer of self-assembled BCP colloidal templates into silicon substrates. The approach for nanofabrication provided unique advantage of highthroughput production of nanotopographies needed for cell-culture, with no compromise on the resolution and quality of samples. The nanopillar arrays are found to enhance osteogenic differentiation of hMSCs, which in turn was found to be dependent on the age of the donor. While cells from young donors showed greatest level of differentiation on large pillar arrays with small pitch, those from an older donor were augmented on large pillars with larger pitch. Further study of the influence of age on differentiation potential, in parallel with a more exhaustive of the influence of nanoscale structures on the behavior of hMSC from patients of various ages can contribute for the advance of personalized cell therapies, and in particular for the treatment of bone diseases and defects. 


\section{AUTHOR INFORMATION}

\section{Corresponding Author}

* S.K.: sivashankar.krishnamoorthy@list.lu, *M.-C.D.: marie-christine.durrieu@inserm.fr

\section{Present Addresses}

${ }^{\perp}$ I.K.: Dr. Panjwani Center for Molecular Medicine and Drug Research, International Center for Chemical and Biological Sciences, University of Karachi, Karachi, Pakistan

\section{Author Contributions}

The manuscript was written through contributions of all authors. All authors have given approval to the final version of the manuscript.

${ }^{\Delta}$ S.K. and M.-C.D. contributed equally for this work.

\section{Funding Sources}

This work was carried out as part of the project EJD-FunMat, which has received funding from the European Union's Horizon 2020 research and innovation program under the Marie Sklodowska-Curie grant agreement No 641640. SK gratefully acknowledges additional funding support from Luxembourg National Research Fund (FNR, Fonds Nationale de la Recherche), via PLASENS (C15/MS/10459961) and MASSENA projects.

\section{ACKNOWLEDGMENT}

The authors gratefully acknowledge the help of K. Menguelti, R. Rastogi and M. Beggiato during nanofabrication, of C. Chanseau for fruitful discussions, and of C. Labrugère for XPS characterization. 


\section{REFERENCES}

(1) Wang, P.-Y.; Thissen, H.; Kingshott, P. Modulation of Human Multipotent and Pluripotent Stem Cells Using Surface Nanotopographies and Surface-Immobilised Bioactive Signals: A $\quad$ Review. Acta Biomaterialia $2016, \quad 45, \quad 31-59$. https://doi.org/10.1016/j.actbio.2016.08.054.

(2) Donnelly, H.; Smith, C.-A.; Sweeten, P. E.; Gadegaard, N.; Meek, R. D.; D’Este, M.; Mata, A.; Eglin, D.; Dalby, M. J. Bone and Cartilage Differentiation of a Single Stem Cell Population Driven by Material Interface. J Tissue Eng 2017, 8, 2041731417705615. https://doi.org/10.1177/2041731417705615.

(3) Stevens, M. M. Biomaterials for Bone Tissue Engineering. Materials Today 2008, 11 (5), 18-25. https://doi.org/10.1016/S1369-7021(08)70086-5.

(4) Kobolak, J.; Dinnyes, A.; Memic, A.; Khademhosseini, A.; Mobasheri, A. Mesenchymal Stem Cells: Identification, Phenotypic Characterization, Biological Properties and Potential for Regenerative Medicine through Biomaterial Micro-Engineering of Their Niche. Methods 2016, 99, 62-68. https://doi.org/10.1016/j.ymeth.2015.09.016.

(5) Harrison, R. G. On the Stereotropism of Embryonic Cells. Science 1911, 34 (870), 279281. https://doi.org/10.1126/science.34.870.279.

(6) Dalby, M. J. Cellular Response to Low Adhesion Nanotopographies. Int J Nanomedicine 2007, 2 (3), 373-381. 
(7) Biggs, M. J. P.; Richards, R. G.; Dalby, M. J. Nanotopographical Modification: A Regulator of Cellular Function through Focal Adhesions. Nanomedicine: Nanotechnology, Biology and Medicine 2010, 6 (5), 619-633. https://doi.org/10.1016/j.nano.2010.01.009.

(8) Kim, M.; Kim, C.; Choi, Y. S.; Kim, M.; Park, C.; Suh, Y. Age-Related Alterations in Mesenchymal Stem Cells Related to Shift in Differentiation from Osteogenic to Adipogenic Potential: Implication to Age-Associated Bone Diseases and Defects. Mechanisms of Ageing and Development 2012, 133 (5), 215-225. https://doi.org/10.1016/j.mad.2012.03.014.

(9) Maredziak, M.; Marycz, K.; Tomaszewski, K. A.; Kornicka, K.; Henry, B. M. The Influence of Aging on the Regenerative Potential of Human Adipose Derived Mesenchymal Stem Cells. Stem Cells International 2016, 2016 (Article ID 2152435), 15. https://doi.org/10.1155/2016/2152435.

(10) Zhou, S.; Greenberger, J. S.; Epperly, M. W.; Goff, J. P.; Adler, C.; LeBoff, M. S.; Glowacki, J. Age-Related Intrinsic Changes in Human Bone-Marrow-Derived Mesenchymal Stem Cells and Their Differentiation to Osteoblasts. Aging Cell 2008, 7 (3), 335-343. https://doi.org/10.1111/j.1474-9726.2008.00377.x.

(11) Alt, E. U.; Senst, C.; Murthy, S. N.; Slakey, D. P.; Dupin, C. L.; Chaffin, A. E.; Kadowitz, P. J.; Izadpanah, R. Aging Alters Tissue Resident Mesenchymal Stem Cell Properties. Stem Cell Research 2012, 8 (2), 215-225. https://doi.org/10.1016/j.scr.2011.11.002.

(12) Ganguly, P.; El-Jawhari, J. J.; Giannoudis, P. V.; Burska, A. N.; Ponchel, F.; Jones, E. A. Age-Related Changes in Bone Marrow Mesenchymal Stromal Cells: A Potential Impact on Osteoporosis and Osteoarthritis Development. Cell Transplant 2017, 26 (9), 1520-1529. https://doi.org/10.1177/0963689717721201. 
(13) Krishnamoorthy, S.; Krishnan, S.; Thoniyot, P.; Low, H. Y. Inherently Reproducible Fabrication of Plasmonic Nanoparticle Arrays for SERS by Combining Nanoimprint and Copolymer Lithography. ACS Appl. Mater. Interfaces 2011, 3 (4), 1033-1040. https://doi.org/10.1021/am1011518.

(14) Brassat, K.; Kool, D.; Bürger, J.; Lindner, J. K. N. Hierarchical Nanopores Formed by Block Copolymer Lithography on the Surfaces of Different Materials Pre-Patterned by Nanosphere Lithography. Nanoscale 2018, $10 \quad$ (21), 10005-10017. https://doi.org/10.1039/C8NR01397G.

(15) Katsumata, R.; Yogeesh, M. N.; Wong, H.; Zhou, S. X.; Sirard, S. M.; Huang, T.; Piner, R. D.; Wu, Z.; Li, W.; Lee, A. L.; Carlson M. C.; Maher, M. J.; Akinwande, D.; Ellison, C. J. Large Area Fabrication of Graphene Nanoribbons by Wetting Transparency-Assisted Block Copolymer $\quad$ Lithography. $\quad$ Polymer $\quad \mathbf{2 0 1 7}, \quad$ 110, $131-138$. https://doi.org/10.1016/j.polymer.2016.12.034.

(16) Cummins, C.; Bell, A. P.; Morris, M. A. Creating Active Device Materials for Nanoelectronics Using Block Copolymer Lithography. Nanomaterials 2017, 7 (10), 304. https://doi.org/10.3390/nano7100304.

(17) George, P. A.; Doran, M. R.; Croll, T. I.; Munro, T. P.; Cooper-White, J. J. Nanoscale Presentation of Cell Adhesive Molecules via Block Copolymer Self-Assembly. Biomaterials 2009, 30 (27), 4732-4737. https://doi.org/10.1016/j.biomaterials.2009.05.039.

(18) Schwab, E. H.; Pohl, T. L. M.; Haraszti, T.; Schwaerzer, G. K.; Hiepen, C.; Spatz, J. P.; Knaus, P.; Cavalcanti-Adam, E. A. Nanoscale Control of Surface Immobilized BMP-2: Toward 
a Quantitative Assessment of BMP-Mediated Signaling Events. Nano Lett. 2015, 15 (3), 15261534. https://doi.org/10.1021/acs.nanolett.5b00315.

(19) Khor, H. L.; Kuan, Y.; Kukula, H.; Tamada, K.; Knoll, W.; Moeller, M.; Hutmacher, D. W. Response of Cells on Surface-Induced Nanopatterns: Fibroblasts and Mesenchymal Progenitor Cells. Biomacromolecules 2007, $8 \quad$ (5), 1530-1540. https://doi.org/10.1021/bm0611533.

(20) Sjöström, T.; McNamara, L. E.; Meek, R. M. D.; Dalby, M. J.; Su, B. 2D and 3D Nanopatterning of Titanium for Enhancing Osteoinduction of Stem Cells at Implant Surfaces. Advanced Healthcare $\quad$ Materials $\quad$ 2013, $\quad 2 \quad$ (9), $1285-1293$. https://doi.org/10.1002/adhm.201200353.

(21) Sjöström, T.; Dalby, M. J.; Hart, A.; Tare, R.; Oreffo, R. O. C.; Su, B. Fabrication of Pillar-like Titania Nanostructures on Titanium and Their Interactions with Human Skeletal Stem Cells. Acta Biomaterialia 2009, 5 (5), 1433-1441. https://doi.org/10.1016/j.actbio.2009.01.007.

(22) McNamara, L. E.; Sjöström, T.; Burgess, K. E. V.; Kim, J. J. W.; Liu, E.; Gordonov, S.; Moghe, P. V.; Meek, R. M. D.; Oreffo, R. O. C.; Su, B.; Dalby M. J. Skeletal Stem Cell Physiology on Functionally Distinct Titania Nanotopographies. Biomaterials 2011, 32 (30), 7403-7410. https://doi.org/10.1016/j.biomaterials.2011.06.063.

(23) de Peppo, G. M.; Agheli, H.; Karlsson, C.; Ekström, K.; Brisby, H.; Lennerås, M.; Gustafsson, S.; Sjövall, P.; Johansson, A.; Olsson, E.; Lausmaa, J.; Thomsen, P.; Petronis, S. Osteogenic Response of Human Mesenchymal Stem Cells to Well-Defined Nanoscale Topography in Vitro. Int $J$ Nanomedicine 2014, 9, 2499-2515. https://doi.org/10.2147/IJN.S58805. 
(24) Biomaterials Science: An Introduction to Materials in Science, 3rd ed.; Ratner, B. D.,

Hoffmann, A. S., Schoen, F. J., Lemons, J. E., Eds.; Elsevier: Canada, 2013. https://doi.org/10.1016/C2009-0-02433-7.

(25) Miron, R. J.; Zhang, Y. F. Osteoinduction: A Review of Old Concepts with New Standards. J Dent Res 2012, 91 (8), 736-744. https://doi.org/10.1177/0022034511435260.

(26) Pfaffl, M. W.; Tichopad, A.; Prgomet, C.; Neuvians, T. P. Determination of Stable Housekeeping Genes, Differentially Regulated Target Genes and Sample Integrity: BestKeeper Excel-Based Tool Using Pair-Wise Correlations. Biotechnology Letters 2004, 26 (6), 509-515. https://doi.org/10.1023/B:BILE.0000019559.84305.47.

(27) Yap, F. L.; Krishnamoorthy, S. Fabricating 2D Arrays of Chemical Templates for in Situ Synthesis of Inorganic Nanostructures Using Self-Assembly Based Nanolithography. J. Mater. Chem. 2010, 20 (45), 10211-10216. https://doi.org/10.1039/C0JM01901A.

(28) Murphy, W. L.; McDevitt, T. C.; Engler, A. J. Materials as Stem Cell Regulators. Nature Materials 2014, 13 (6), 547-557. https://doi.org/10.1038/nmat3937.

(29) Das, R. K.; Gocheva, V.; Hammink, R.; Zouani, O. F.; Rowan, A. E. Stress-StiffeningMediated Stem-Cell Commitment Switch in Soft Responsive Hydrogels. Nat Mater 2016, 15 (3), 318-325. https://doi.org/10.1038/nmat4483.

(30) Lamplot, J. D.; Denduluri, S.; Liu, X.; Wang, J.; Yin, L.; Li, R.; Shui, W.; Zhang, H.; Wang, N.; Nan, G.; Angeles J.; Shi, L. L.; Haydon, R. C.; Luu, H. H.; Ho, S.; He, T.-C.; Zhao, R. C. Major Signaling Pathways Regulating the Proliferation and Differentiation of 
Mesenchymal Stem Cells. In Essentials of Mesenchymal Stem Cell Biology and Its Clinical Translation; Zhao, R. C., Ed.; Springer Netherlands, 2013; pp 75-100.

(31) Biggs, M. J. P.; Fernandez, M.; Thomas, D.; Cooper, R.; Palma, M.; Liao, J.; Fazio, T.; Dahlberg, C.; Wheadon, H.; Pallipurath, A.; Pandit, A.; Kysar, J.; Wind, S. J. The Functional Response of Mesenchymal Stem Cells to Electron-Beam Patterned Elastomeric Surfaces Presenting Micrometer to Nanoscale Heterogeneous Rigidity. Adv. Mater. 2017, 29 (39), n/a-n/a. https://doi.org/10.1002/adma.201702119.

(32) Maier, T.; Güell, M.; Serrano, L. Correlation of MRNA and Protein in Complex Biological Samples. FEBS Letters 2009, $583 \quad$ (24), $\quad$ 3966-3973. https://doi.org/10.1016/j.febslet.2009.10.036.

(33) Vogel, C.; Marcotte, E. M. Insights into the Regulation of Protein Abundance from Proteomic and Transcriptomic Analyses. Nature Reviews Genetics 2012, 13 (4), 227-232. https://oi.org/10.1038/nrg3185.

(34) Gui, N.; Xu, W.; E. Myers, D.; Shukla, R.; P. Tang, H.; Qian, M. The Effect of Ordered and Partially Ordered Surface Topography on Bone Cell Responses: A Review. Biomaterials Science 2018, 6 (2), 250-264. https://doi.org/10.1039/C7BM01016H.

(35) Ishchenko, O. M.; Krishnamoorthy, S.; Valle, N.; Guillot, J.; Turek, P.; Fechete, I.; Lenoble, D. Investigating Sequential Vapor Infiltration Synthesis on Block-CopolymerTemplated Titania Nanoarrays. J. Phys. Chem. C 2016, 120 (13), 7067-7076. https://doi.org/10.1021/acs.jpcc.5b10415. 
(36) Park, C.; Yoon, J.; Thomas, E. L. Enabling Nanotechnology with Self Assembled Block Copolymer Patterns. Polymer 2003, $44 \quad$ (22), 6725-6760. https://doi.org/10.1016/j.polymer.2003.08.011.

(37) McMurray, R. J.; Gadegaard, N.; Tsimbouri, P. M.; Burgess, K. V.; McNamara, L. E.; Tare, R.; Murawski, K.; Kingham, E.; Oreffo, R. O. C.; Dalby, M. J. Nanoscale Surfaces for the Long-Term Maintenance of Mesenchymal Stem Cell Phenotype and Multipotency. Nat Mater 2011, 10 (8), 637-644. https://doi.org/10.1038/nmat3058.

(38) Zhang, Q.; Lin, S.; Li, Q.; Zhao, D.; Cai, X. Cellular Response to Surface Topography and Substrate Stiffness. In Cartilage Regeneration; Lin, Y., Ed.; Stem Cell Biology and Regenerative Medicine; Springer International Publishing: Cham, 2017; pp 41-57. https://doi.org/10.1007/978-3-319-51617-2_3.

(39) Lee, L. C. Y.; Gadegaard, N.; de Andrés, M. C.; Turner, L.-A.; Burgess, K. V.; Yarwood, S. J.; Wells, J.; Salmeron-Sanchez, M.; Meek, D.; Oreffo, R. O. C.; Dalby, M. J. Nanotopography Controls Cell Cycle Changes Involved with Skeletal Stem Cell Self-Renewal $\begin{array}{lllll}\text { and } & \text { Multipotency. } & \text { Biomaterials } & \text { 2017, }\end{array}$ https://doi.org/10.1016/j.biomaterials.2016.11.032. 
TABLE OF CONTENTS GRAPHIC

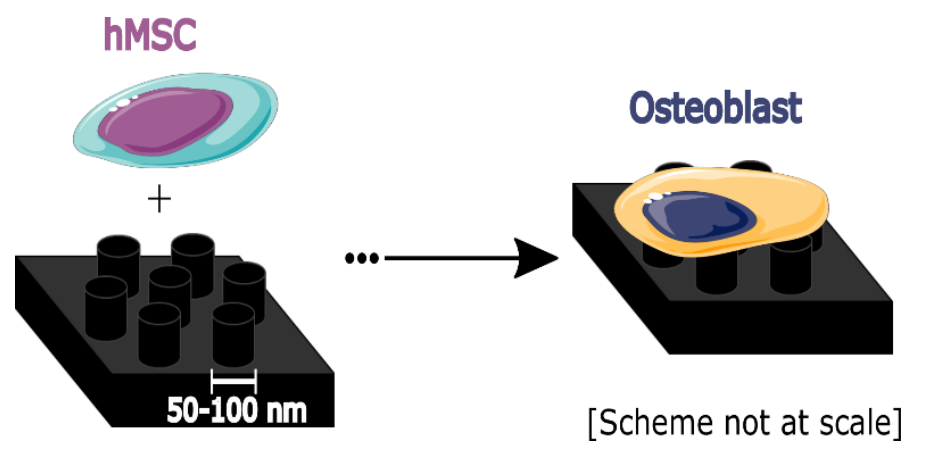

37 